\title{
Eosinophils and eosinophil-derived proteins in children with moderate asthma
}

\author{
M.O. Hoekstra*, H. Hovenga**, J. Gerritsen*, H.F. Kauffman**
}

Eosinophils and eosinophil-derived proteins in children with moderate asthma. M.O. Hoekstra, H. Hovenga, J. Gerritsen, H.F. Kauffman. COERS Journals Ltd 1996.

ABSTRACT: Laboratory parameters can contribute to the diagnosis of asthma, which is often a difficult procedure in paediatric patients. The aim of this study was to investigate the value of esinophil cationic protein (ECP) and eosinophilderived neurotoxin (EDN) in the diagnosis of paediatric asthma.

The number of eosinophils, serum ECP and EDN, and urinary EDN were determined in 22 children with stable, allergic asthma, aged 4-14 yrs, and in 17 agematched healthy controls. Symptoms were monitored, the peak expiratory flow rate (PEFR) was recorded in the younger children, and lung function tests (forced expiratory volume in one second (FEV1) and the provocative concentration of histamine causing a $20 \%$ fall in FEV1 (PC20)) were performed in the older children. None of the asthmatic children had respiratory symptoms. PEFR was not significantly different in asthmatic children compared to controls. The FEV1 \% predicted was significantly lower compared to controls.

The number of eosinophils, serum ECP and EDN, and urinary EDN were significantly higher in asthmatic children compared with controls. After correction of serum ECP and EDN, and urinary EDN for the number of eosinophils, the differences between patients and controls disappeared. The nocturnal PEFR and the FEV1 were significantly related to urinary EDN.

The results suggest that serum and urinary concentration of eosinophil-derived proteins can be determined instead of the number of eosinophils to support the diagnosis of asthma in childhood. The urinary concentration of eosinophil-derived neurotoxin can be especially valuable in young children, because in this age group quantification of lung function cannot be performed and blood sampling can be difficult.

Eur Respir J., 1996, 9, 2231-2235.

Asthma is a common disease of childhood. The diagnosis of asthma is based on the presence of well-described clinical signs and symptoms [1]. Laboratory tests, such as eosinophil count in peripheral blood, can be supportive in the diagnosis of asthma. The eosinophilic granulocyte is an important proinflammatory cell in the pathogenesis of asthma [2]. Several investigations have found an increased number of eosinophils in the peripheral blood of asthmatic patients compared to healthy controls [3-5]. During airway inflammation, eosinophils release proteins, such as eosinophilic cationic protein (ECP) and eosinophil-derived neurotoxin (EDN) (=eosinophil protein $\mathrm{X}(\mathrm{EPX})$ ), which are toxic to respiratory epithelium [6]. An increase in serum ECP is found in asthmatic patients, and a relationship between serum ECP and both disease activity [4, 5] and lung function [5] in asthma has been reported. ECP is also elevated in patients with nocturnal asthma [7]. EDN/EPX is an eosinophil-derived ribonuclease [8,9]. An increase of serum EDN/EPX has been reported in asthmatic patients [5]. EDN/EPX has been quantified in urine of healthy persons, but it has never been measured in the urine of asthmatic patients [10]. Since EDN/EPX is produced especially by eosinophils, we decided to measure EDN/ EPX in the urine of asthmatic children and controls.
The aim of the present study was to determine serum and urine concentrations of eosinophil-derived proteins in children, and to examine whether the levels could be related to the diagnosis of asthma.

\section{Methods}

\section{Subjects}

A group of 22 children aged 4-14 yrs, having diagnosed allergic asthma (according to the American Thoracic Society (ATS) criteria [1]) with perennial symptoms, and 17 healthy controls participated in the study. They were recruited from the paediatric out-patient department and from general practitioners in Groningen. Allergy was defined as the presence of an increased total immunoglobulin E ( $\operatorname{IgE}$ ) (corrected for age) and at least one increased specific IgE against an inhalant allergen. Lung function at the onset of the study of all the patients showed bronchial hyperresponsiveness (defined as the presence of a provocative concentration of histamine causing a $20 \%$ fall in forced expiratory volume in one second $\left.(\mathrm{PC} 20)<8 \mathrm{mg} \cdot \mathrm{mL}^{-1}\right)$. The patients did not use any maintenance treatment for at least 4 weeks prior to 
the study. Children who used systemic corticosteroids on more than three occasions in the 6 months prior to the study were excluded.

Controls were recruited from schools in the city of Groningen and had no symptoms or signs of asthma or allergy. Their family histories were negative for asthma and allergy. Total IgE concentration was within the normal range for age, and specific $\operatorname{IgE}$ was negative for the panel of allergens. During lung function testing, there was no fall in forced expiratory volume in one second (FEV1) at the maximum histamine provocation dose of $16 \mathrm{mg} \cdot \mathrm{mL}^{-1}$. The characteristics of patients and controls are presented in table 1.

\section{Study design}

All participants visited the out-patient department (OPD) in the morning between 08:00 and 10:00 h. Morning urine, collected at home between 06:00 and 07:00 h, was sampled and stored at $-20^{\circ} \mathrm{C}$. A history was taken and physical examination was performed. Subsequently, blood samples were taken under fasting conditions, and in children $>8$ yrs lung function was performed. Children $<8$ yrs performed a peak flow registration in the morning and in the evening for 7 days following the visit to the out-patient department.

\section{Symptom score}

Respiratory symptoms, such as wheezing, cough, sputum production and dyspnoea were recorded in a diary record card during the first 7 days after the visit to the OPD.

\section{Peak flow recording}

Peak expiratory flow rate (PEFR) was measured at home each day in the morning and in the evening using a mini-Wright peak flow meter during the 7 days after

Table 1. - Characteristics of the participants

\begin{tabular}{lccc}
\hline Characteristics & Patients & Controls & p-value \\
\hline Number & 22 & 17 & - \\
Age yrs & $9 \pm 1$ & $10 \pm 1$ & NS \\
Sex M/F & $16 / 6$ & $7 / 9$ & NS \\
IgE U.mL & $429(212-859)$ & $22(11-51)$ & $\dagger$ \\
PEFRm \% pred & $84 \pm 6(n=8)$ & $95 \pm 4(n=8)$ & NS \\
PEFRe \% pred & $83 \pm 5(n=8)$ & $93 \pm 4(n=7)$ & NS \\
PEFRn \% pred & $72 \pm 6(n=5)$ & $88 \pm 5(n=7)$ & NS \\
FEV1 \% pred & $84 \pm 3(n=12)$ & $107 \pm 3(n=8)$ & $<0.001$ \\
FEV1/VC \% & $77 \pm 3(n=12)$ & $89 \pm 2(n=8)$ & 0.01 \\
PC20 mg.mL mL $^{-1}$ & $1.88 \pm 0.578(n=12)$ & $>16(n=8)$ & + \\
\hline
\end{tabular}

Values are presented as geometric mean \pm SEM, except IgE, which is presented as geometric mean with interquartile ranges $(25-75 \%) . \dagger$ : this variable was used as an inclusion criterion; ${ }^{+}:$this variable was used as inclusion criterion in the children who could perform spirometry. M: male; F: female; IgE: immunoglobulin E; PEFR; peak expiratory flow rate; $\mathrm{m}$ : in the morning; e: in the evening; n: at night-time (04:00 h); FEV1: forced expiratory volume in one second; $\%$ pred: percentage of predicted value according to gender and height of the child; VC: vital capacity; PC20: provocative concentration of histamine causing a $20 \%$ fall in FEV1; Ns: nonsignificant. the visit to the OPD. The PEFR was recorded as the best of 3 measurements. PEFR values from the first three days were regarded as practice and were, therefore, not included in the calculations. PEFR values from the last 4 days were used to calculate the individual mean PEFR. On one day of the last 4 days at $04.00 \mathrm{~h}$, the nocturnal PEFR was determined by the patients. To compensate for age-related differences in PEFR, each individual PEFR was expressed as a percentage of the PEFR predicted for age before calculating the mean PEFR of patients and controls. Diurnal peak flow variation was calculated as the difference between evening and morning PEFR $(\triangle \mathrm{PEFRe}-\mathrm{m})$ and as the difference between evening and night PEFR ( $\triangle$ PEFRe-n).

\section{Lung function}

Patients were asked to refrain from taking salbutamol during $12 \mathrm{~h}$ prior to the visit to the OPD. After measuring FEV1 and vital capacity (VC) (on a Lode water-sealed spirometer, The Netherlands) bronchial hyperresponsiveness was determined by histamine provocation test, as described previously [11]. Briefly, PC20 was measured by inhalation of histamine-diphosphate in doubling doses according to a standardized protocol. Each concentration of histamine was nebulized with a separate de Vilbiss 646 nebulizer attached to a RosenthalFrench dosimeter. Inhaled concentrations of histamine were doubled from 0.25 up to $16 \mathrm{mg} \cdot \mathrm{mL}^{-1}$ as a maximum. The effect of each dose was measured 3 min after administration. The $\mathrm{PC} 20$ was defined as the concentration of histamine causing a $20 \%$ fall in FEV1. The exact PC20 was assessed by linear interpolation of the last two points of the log concentration response curve.

\section{Number of eosinophils}

Peripheral ethylenediamine tetra-acetic acid (EDTA) treated blood was diluted 10 times and stained with an eosin-formalin solution, consisting of $2.5 \mathrm{~mL}$ formalin and $25 \mathrm{~mL}$ eosin $1 \%$ per $250 \mathrm{~mL}$ distilled water. Dilution was performed with a Finnpipette Diluter (Labsystems, Helsinki, Finland). In this way, erythrocytes were lysed and eosinophils were stained. Eosinophils were counted with a Neubauer counting chamber.

\section{IgE concentration}

Total IgE antibody concentration and specific IgE antibody concentration (for major inhaled allergens:house dust mite, grass pollen, tree pollen, dog dander and cat dander) were determined with the Immuno CAP Technique according to the protocol of the manufacturer (Pharmacia, Uppsala, Sweden). The range of $\operatorname{IgE}$ with this method was 2-2000 U.mL-1. Values above 2,000 U.mL-1 were further quantified by dilution.

\section{Determination of ECP and EDN}

After the blood sample was taken, it was allowed to clot for $1 \mathrm{~h}$ at room temperature. Subsequently, the tubes were centrifuged twice at $1,450 \times \mathrm{g}$, and the serum 
was collected and stored at $-20^{\circ} \mathrm{C}$. Serum ECP and EDN and urinary EDN were determined by radioimmunoassay according to a previously described method [11] (Pharmacia, Uppsala, Sweden). The range of ECP was $0-200 \mu \mathrm{g} \cdot \mathrm{L}^{-1}$ and the range of EDN was $0-400 \mu \mathrm{g} \cdot \mathrm{L}^{-1}$. Values above the upper detection limits were further quantified after dilution. Urinary EDN concentration divided by creatinine concentration (urinary EDN/Cr) was calculated after determining the concentration of creatinine in morning urine.

\section{Data analysis}

Before calculations were made, all variables with a non-Gaussian shaped distribution (IgE, serum ECP and EDN, urinary EDN, and urinary EDN/Cr) were log-transformed in order to obtain a Gaussian shaped distribution. Subsequently, comparison of mean values was performed using the Student's t-test, with the exception of ECP. The variables with a Gaussian shaped distribution (PEF values, FEV1 \% pred, and the number of eosinophils) are shown as the geometric mean \pm SEM. All variables with a non-Gaussian distribution (IgE, serum ECP and EDN, urinary EDN, and urinary EDN/Cr) are shown as geometric mean and interquartile ranges $(25 \%$ and $75 \%)$, with the exception of ECP. Because two controls had a negative $\log$ ECP value (ECP between 0 and 1), the mean ECP value in controls could not be calculated after logtransformation of ECP values. As a consequence, mean ECP values in patients and controls were compared with Mann Whitney U-test, and ECP values are shown as mediantinterquartile ranges. A p-value less then 0.01 was considered to denote statistical significance. This $p$ value was chosen instead of the usual value of 0.05 to take into account the fact that multiple comparisons were made. Correlation between variables was performed with Pearson's correlation test. All analyses were performed with the Statistical Package for the Social Sciences (SPSS)/ PC+ package.

\section{Informed consent}

The study was approved by the Medical Ethics Committee of the University Hospital of Groningen. The patients and their parents gave informed consent.

Table 2. - Laboratory parameters

\begin{tabular}{|c|c|c|c|}
\hline Parameter & Patients & Controls & p-value \\
\hline $\begin{array}{l}\text { Eosinophil } \\
\text { count }^{+} \text {cells } \cdot \mathrm{mL}^{-1}\end{array}$ & $872 \pm 122$ & $308 \pm 62$ & 0.001 \\
\hline Serum ECP* $\mu \mathrm{g} \cdot \mathrm{L}^{-1}$ & $\begin{array}{c}9.45 \\
(6.2-12.7)\end{array}$ & $\begin{array}{c}2.9 \\
(1.2-5.9)\end{array}$ & $\begin{array}{l}0.005 \\
0.005\end{array}$ \\
\hline Serum EDN\# $\mu \mathrm{g} \cdot \mathrm{L}^{-1}$ & $\begin{array}{c}31.8 \\
(23.3-40.7)\end{array}$ & $\begin{array}{c}15.4 \\
(10.3-23)\end{array}$ & $<0.001$ \\
\hline $\mathrm{EDNu}^{\#} \mu \mathrm{g} \cdot \mathrm{L}^{-1}$ & $\begin{array}{c}1148 \\
(610-2692)\end{array}$ & $\begin{array}{c}585 \\
(438-782)\end{array}$ & $\begin{array}{l}0.01 \\
0.01\end{array}$ \\
\hline $\mathrm{EDNu} / \mathrm{Cr}^{\#}$ & $\begin{array}{c}162 \\
(91-20)\end{array}$ & $\begin{array}{c}55 \\
(34-79)\end{array}$ & $\begin{array}{l}<0.005 \\
<0.005\end{array}$ \\
\hline
\end{tabular}

+: geometric mean \pm SEM; $*$ : median and interquartile range (25-75\%); \#: geometric mean and interquartile range (25-75\%). ECP: eosinophil cationic protein; EDN: eosinophil-derived neurotoxin; EDNu: urinary EDN; Cr: creatinine.

\section{Results}

\section{Symptom score}

All the patients were in a stable phase of their asthma and reported no symptoms of cough, wheezing or dyspnoea at the time of the study and in the following week.

\section{Peak flow recording (PEFR)}

Although PEFR values were lower and changes in PEFR were higher in patients than in controls, these differences did not reach statistical significance (table 1).

\section{Lung function}

FEV1 was significantly lower in patients $(84 \pm 3 \%$ pred) than in controls $(107 \pm 3 \%$ pred), as was FEV1/ $\mathrm{VC}$ (shown as the ratio of FEV1 and VC multiplied by $100 \%)(77 \pm 3 \%$ in patients/89 $\pm 2 \%$ in controls) (table 1$)$.

\section{Number of eosinophils, serum ECP and EDN, urinary} EDN and urinary EDN/Cr

The number of eosinophils was significantly higher in patients $\left(872 \pm 122\right.$ cells $\left.\cdot \mathrm{uL}^{-1}\right)$ than in controls $(308 \pm$ 62 cells $\left.\cdot \mu \mathrm{L}^{-1}\right)$. Serum ECP and EDN, urinary EDN and urinary EDN/Cr were also significantly higher in the patients than in the controls (table 2 and fig. 1). After correction of serum ECP and EDN, urinary EDN and

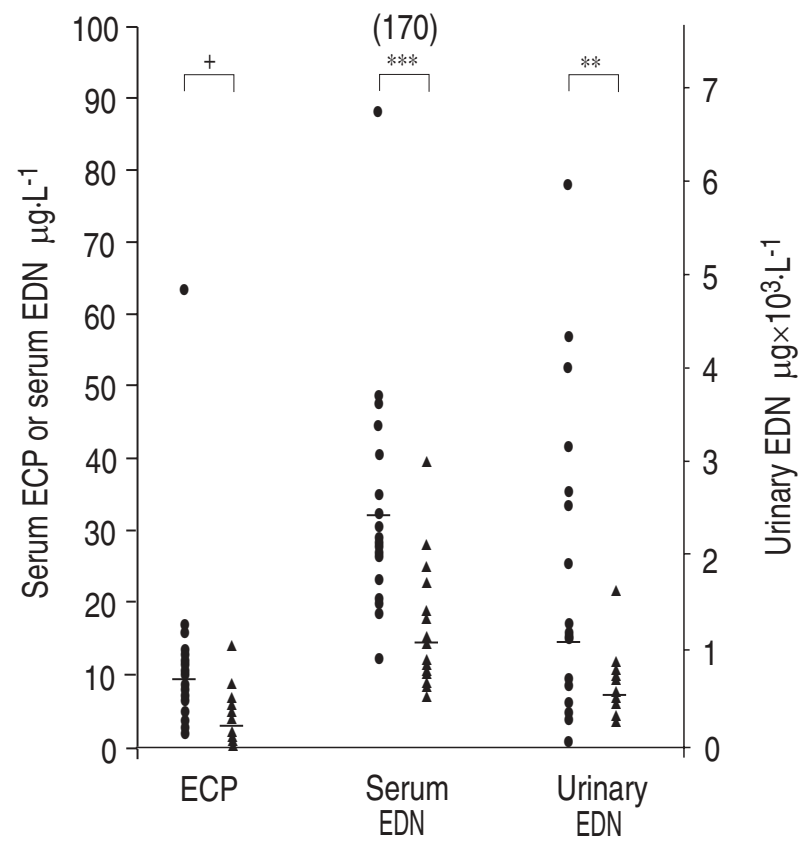

Fig. 1. - Serum ECP, serum EDN, and urinary EDN, concentrations. Patients are indicated by circles and controls are indicated by triangles. The geometric means were equal to the median values and are indicated by horizontal bars. One outlying value is indicated at the top of the figure in parenthesis by its actual value. ECP: eosinophil cationic protein; EDN: eosinophil-derived neurotoxin. ${ }^{+}: \mathrm{p}<0.005$; $* *$ : $\mathrm{p}<0.01 ; * * *: \mathrm{p}<0.001$. 


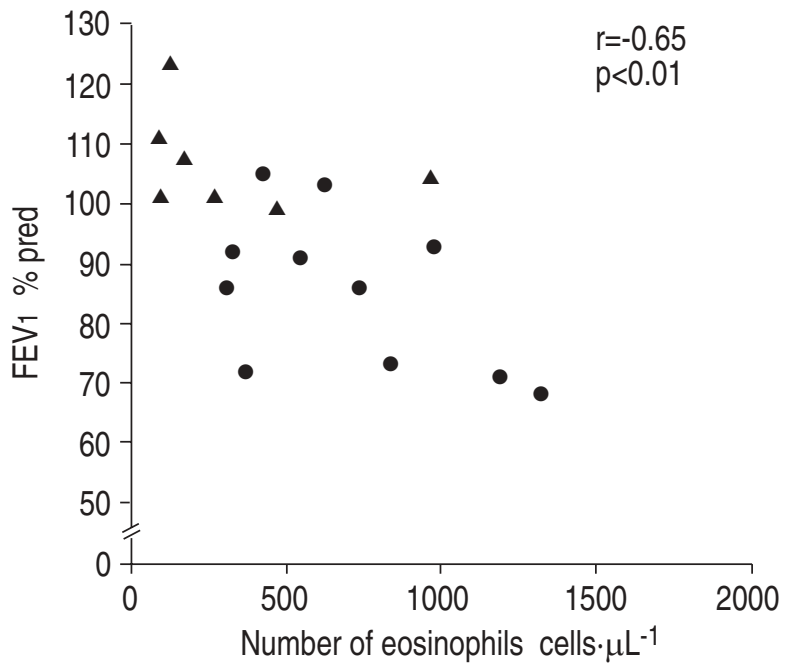

Fig. 2. - FEV1 as a function of the number of eosinophils. Patients are indicated by circles and controls are indicated by the triangles. FEV1: forced expiratory volume in one second; \% pred: percentage of predicted value according to gender and height of the child.

urinary EDN/Cr for the number of eosinophils, the differences between patients and controls were no longer significant.

\section{Correlation between laboratory parameters and lung function parameters}

The morning and evening PEFR and $\triangle$ PEFR values were not significantly related to any of the laboratory parameters. The nocturnal PEFR was inversely related to urinary EDN/Cr $(r=-0.77 ; \mathrm{p}<0.001)$. The relationship between the nocturnal PEFR and urinary EDN was of borderline significance $(\mathrm{r}=-0.65 ; \mathrm{p}<0.03)$. FEV1 \% pred was inversely related to the eosinophil count $(\mathrm{r}=$ -0.65; $\mathrm{p}<0.01$ ) (fig. 2), to urinary $\operatorname{EDN}(\mathrm{r}=-0.65 ; \mathrm{p}<0.01)$ (fig. 3) and to urinary EDN/Cr $(\mathrm{r}=-0.64 ; \mathrm{p}<0.01)$. $\mathrm{PC} 20$ was not related to the eosinophil count, serum ECP or $\mathrm{EDN}$, urinary EDN or urinary $\mathrm{EDN} / \mathrm{Cr}$ in the group of asthmatic children.

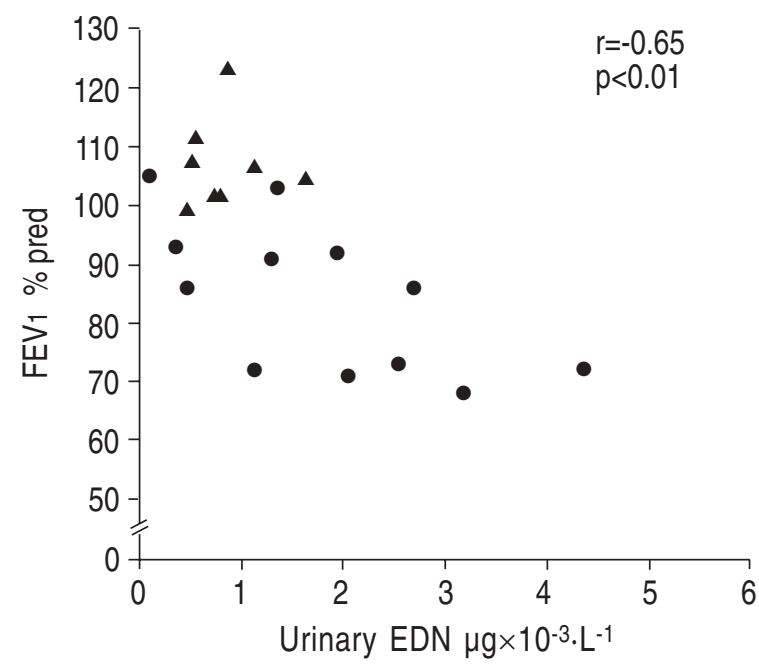

Fig. 3. - FEV1 as a function of urinary EDN. Patients are indicated by circles and controls are indicated by triangles. For definitions see tables 1 and 2 .

\section{Discussion}

We found that serum concentration of ECP and EDN and the urinary concentration of EDN were significantly higher in children with atopic asthma than in healthy controls. A significant relationship was found between FEV1 and both the number of eosinophils in peripheral blood and the concentration of eosinophil-derived proteins in urine.

Other investigators have reported on the number of eosinophils and the serum concentration of eosinophilderived proteins in asthmatic adults [12-18], and in asthmatic children $[4,5,18,19]$. A comparison of the number of eosinophils and the concentration of eosinophil-derived proteins between asthmatic children and healthy controls was described previously $[4,5]$. Our results are in accordance with the observations that the number of eosinophils [4, 5], ECP [4, 5] and serum EDN [5] are significantly higher in children with asthma than in controls. In both previous studies [4, 5], the concentration of ECP in the asthmatic children was higher than found in the present study. This might be due to differences in patient characteristics, as our patients suffered from relatively mild and stable asthma. The difference in ECP in asthmatic children reported in some studies might also be attributable to a difference in technique of blood sample handling. It has been shown that differences in time and temperature of storage of blood samples in the laboratory may influence the quantity of serum ECP generated [20].

An important difference between the present study and the previous studies $[4,5]$, is that we made a correction of the concentration of eosinophil-derived proteins for the number of eosinophils. This calculation seems to be justified, since eosinophils are the only cells in the body that produce these proteins. This correction was made in order to calculate the contribution of the number of eosinophils to the concentration of these proteins. After correction, it was found that the difference in eosinophil-derived proteins between asthmatic children and controls disappeared. This result indicates that the number of eosinophils in circulation is reflected in the serum and urinary concentrations of eosinophil-derived proteins. Thus, serum ECP, serum EDN and urinary EDN are not of additional value in discriminating children with and without asthma. This conclusion is in accordance with previously published data $[4,5]$.

This is the first study of urinary concentrations of EDN in asthmatic children, based on a method of determination described previously [8]. Urinary EDN was significantly higher in asthmatic children than in controls, although an overlap was observed. This overlap in values may be explained by the presence of different types of ribonucleases that have been identified in human urine. It cannot be excluded that the EDN assay used in this study cross-reacts with several ribonucleases. However, it was also found that urinary EDN was significantly related to nocturnal PEFR and to FEV1, which suggests that the difference in urinary EDN between patients and controls is associated with asthma. It is remarkable that a significant relationship was found between lung function and urinary EDN, but not with the serum parameters. This may be explained by the fact that serum ECP and EDN and urinary EDN reflect 
eosinophils in a different way. Since morning urine is collected over several hours, the concentration of EDN in morning urine represents an integration of EDN levels during several hours, whereas serum ECP and serum EDN reflect values at only one time-point. Thus, urinary EDN reflects eosinophil number over a period of time, compared with serum ECP and EDN, which reflect eosinophil numbers at a particular moment. As the release and apoptosis of eosinophils and the degranulation of the cell is a dynamic process, it can be imagined that urinary EDN is a more complete reflection of the eosinophil cell than serum ECP or EDN. The present findings suggest that the determination of urinary EDN could be a simple and less invasive alternative to the determination of blood eosinophils when the diagnosis of childhood asthma is considered. In young children, in particular, this can be a useful parameter, since blood sampling in young children can be difficult.

It is not yet clear whether eosinophil-derived proteins are increased due to atopy rather than to asthma, or whether they are elevated in other disorders characterized by eosinophilic inflammation. Another issue for future study is the value of serum and urinary eosinophil-derived proteins in monitoring asthma, for which longitudinal clinical trials have to be performed.

In conclusion, our results suggest that the determination of the serum and urine concentrations of eosinophil-derived proteins can be determined instead of the number of eosinophils to diagnose asthma in children. The urinary concentration of eosinophil-derived neurotoxin might be an important additional and noninvasive tool in asthmatic children. Before definitive conclusions can be drawn on the value of eosinophil cationic protein and eosinophil-derived neurotoxin with respect to the diagnosis of childhood asthma, additional studies have to be carried out.

Acknowledgements: The authors thank Pharmacia BV (Woerden, The Netherlands) for the generous supply of ECP and EDN assays. They also thank A.E.J. Dubois, for critically reviewing this manuscript.

\section{References}

1. Burrows B, Huang N, Hughes R, et al., from the ACCPATS joint committee on pulmonary nomenclature. Pulmonary terms and symbols. Chest 1975; 67: 583593.

2. Kay AB. Asthma and inflammation. J Allergy Clin Immunol 1991; 87: 893-910.

3. Horn BR, Robin ED, Theodore J, Van Kessel A. Total eosinophil counts in the management of bronchial asthma. N Engl J Med 1975; 292: 1152-1155.

4. Sugai T, Sakiyama Y, Matumoto S. Eosinophil cationic protein in peripheral blood of pediatric patients with allergic diseases. Clin Exp Allergy 1992; 22: 275281.

5. Zimmerman B, Lanner A, Enander I, Zimmerman RS, Peterson CG, Ahlstedt S. Total blood eosinophils, serum eosinophil cationic protein and eosinophil protein $\mathrm{X}$ in childhood asthma. Clin Exp Allergy 1993; 23: 564-570.
6. Gleich GJ. The eosinophil and bronchial asthma: current understanding. J Allergy Clin Immunol 1990; 85: 422-436.

7. Oosterhoff Y, Kauffman HF, Rutgers B, Zijlstra FJ, Koëter GH, Postma DS. Inflammatory cell number and mediators in bronchoalveolar lavage fluid and peripheral blood in subjects with asthma with increased nocturnal airways narrowing. J Allergy Clin Immunol 1995; 96: 219-229.

8. Slifman SR, Loegering DA, McKean DJ, Gleich GJ. Ribonuclease activity associated with human eosinophil-derived neurotoxin and eosinophil cationic protein. J Immunol 1986; 137: 2913-2917.

9. Beintema JJ, Hofsteenge J, Iwama M, et al. Amino acid sequence of the nonsecretory ribonuclease of human urine. Biochemistry 1988; 27: 4530-4538.

10. Reimert CM, Minuva U, Kharazmi A, Bendtzen K. Eosinophil protein X/eosinophil-derived neurotoxin (EPX/EDN): detection by enzyme-linked immunosorbent assay and purification from normal human urine. J Immunol Methods 1991; 141: 97-104.

11. Roorda RJ, Gerritsen J, Aalderen WMC v, Schouten JP, Knol K. Repeated provocation tests in asthmatic children for testing tachyphylaxis to histamine. Ped Pulmonol 1991; 10: 106-111.

12. Carlsson M, Håkansson L, Peterson C, Stålenheim G, Venge P. Secretion of granule proteins from eosinophils and neutrophils is increased in asthma. J Allergy Clin Immunol 1991; 87: 27-33.

13. Peterson CGB, Enander I, Nystrand J, Anderson AS, Nilsson L, Venge P. Radioimmunoassay of human eosinophilic cationic protein (ECP) by an improved method: establishment of normal levels in serum and turnover in vivo. Clin Exp Allergy 1991; 21: 561-567.

14. Griffin E, Hakansson L, Formgren H, Jorgensen K, Peterson Ch, Venge P. Blood eosinophil number and activity in relation to lung function in patients with asthma and with eosinophilia. J Allergy Clin Immunol 1991; 87: 548-557.

15. Venge P, Roxin LE, Olsson I. Radioimmunoassay of human eosinophil cationic protein. Br J Haematol 1977; 74: 564-568.

16. Durham SR, Loegering DA, Dunnette S, Gleich GJ, Kay AB. Blood eosinophils and eosinophil-derived proteins in allergic asthma. J Allergy Clin Immunol 1989; 84: 931-936.

17. Venge P, Hakansson L, Peterson Ch. Eosinophil activation in allergic disease. Int Arch Allergy Appl Immunol 1987; 82: 333-337.

18. Zimmerman B, Enander I, Zimmerman RS, Ahlstedt S. Asthma in children less than 5 years of age: eosinophils and serum levels of the eosinophil proteins ECP and EPX in relation to atopy and symptoms. Clin Exp Allergy 1994; 24: 149-155.

19. Niggeman B, Kleinau I, Schmitt M, Wahn U. Twenty four hour time course of eosinophil granule proteins ECP and EPX during bronchial allergen challenges in serum of asthmatic children. Allergy 1994; 44: 74-80.

20. Pronk-Admiraal CJ, Bartels PCM. Effect of clotting temperature and eosinophil concentration on the eosinophil cationic protein concentration in serum. Scand J Clin Lab Invest 1994; 54: 185-188. 